\title{
A venda e o aluguel no Programa Minha Casa Minha Vida - Faixa 1 em Parnamirim/RN
}

\author{
The selling and renting of houses on the program "Minha Casa Minha Vida" in \\ Parnamirim/RN
}

Carina Aparecida Barbosa Mendes Chaves [a] (1)

[a] Universidade Federal do Rio Grande do Norte (UFRN), Programa de Pós-graduação em Estudos Urbanos e Regionais, Natal, RN, Brasil

Como citar: Chaves, C. A. B. M. (2019). A venda e o aluguel no programa Minha Casa Minha Vida - Faixa 1 em Parnamirim/RN. urbe. Revista Brasileira de Gestão Urbana, 11, e20180033. https://doi.org/10.1590/21753369.011.e20180033

\section{Resumo}

Em 2009, por meio da Lei no 11.977, foi lançado o Programa Minha Casa Minha Vida (PMCMV). As regras que regulamentam a faixa 1 do programa exprimem que a finalidade é oferecer habitação às famílias contempladas com o imóvel subsidiado e que qualquer tipo de contrato de cessão de direitos não tem validade legal. Porém, observam-se, por intermédio de pesquisas de campo, anúncios ou reportagens, a comercialização ou a locação dos imóveis. Este trabalho se propõe a analisar as operações de venda e de locação do PMCMV faixa 1 em Parnamirim, Rio Grande do Norte, no período de 2011 a 2016, momento em que recebeu 4.224 unidades habitacionais. Para a realização desta pesquisa, foram utilizados bibliografia nacional sobre o tema, acesso às leis que regulam o programa, coleta e tabulação de classificados on-line e pesquisa de campo nos empreendimentos do PMCMV em Parnamirim. Verificou-se que, nos empreendimentos faixa 1 de Parnamirim, existem imóveis à venda, assim como moradores que residem na condição de locatário. Observou-se também que os imóveis alugados e/ou à venda, em sua maioria, estão situados em áreas afastadas da malha urbana ou em lugares que têm sido valorizados nos últimos anos.

Palavras-chave: Parnamirim. Programa Minha Casa Minha Vida. Venda. Aluguel.

\section{Abstract}

In 2009, through the Law 11.977, the "My House My Life" Program (PMCMV) was launched. The rules that regulate the section 1 of the program state that the purpose is to provide housing for the families contemplated with the subsidized property and that any type of assignment agreement has no legal validity. However, either through urban surveys, advertisements or reports, the sale or lease of them is observed. This work proposes to analyze the sale and renting operations of the PMCMV category 1 in Parnamirim/RN, from 2011 to 2016, at which time it received 4,224 housing units. To develop this research, a national bibliography on the subject, access to the laws that regulate the program, collection, and tabulation of online classifieds and field research in PMCMV's projects in Parnamirim were used. 
In the estates 1 of Parnamirim, there are properties for sale, as well as residents living in the condition of a renter. The localities with the highest number of properties rented and/or offered for sale are situated in locations far from the urban network or in places that have been valued in recent years.

Keywords: Parnamirim. "Minha Casa Minha Vida" Program. Sale. Rent.

\section{Introdução}

O Programa Minha Casa Minha Vida (PMCMV), criado em 2009, é avaliado positivamente por sua magnitude (1 milhão de unidades na primeira fase e 2,750 milhões na segunda fase) e pela inclusão de subsídios diretos a famílias de até dez salários mínimos, sendo a faixa 1 contemplada com subsídios de até $95 \%$ do valor do imóvel (CEF, 2012). No entanto, o programa é alvo de críticas relacionadas às dificuldades de inserção da população no padrão habitacional e na tipologia das construções e à localização dos empreendimentos, os quais, por terem a construção e a escolha das localidades controladas pela dinâmica do mercado, foram, em sua maioria, construídos nas periferias das cidades (Amore et al., 2015; Cardoso \& Aragão, 2013). A primeira crítica deve-se, sobretudo, ao padrão de condomínios implementado em muitos conjuntos construídos, pois, além do estabelecimento de regras de convivência diferentes do que grande parte da população estava acostumada, gerou um novo custo à sua moradia. Quanto à localização, esse aspecto caracteriza-se como um agravante à locomoção diária para as localidades dos trabalhos, das instituições educacionais, das unidades de atendimento à saúde, dentre outros, e reflete no orçamento das famílias. Cardoso \& Aragão (2013, p. 48-49) advertem que

[...] o processo de periferização dos novos empreendimentos, no entanto, deve ser analisado à luz da especificidade de cada cidade, já que a dinâmica metropolitana recente tem levado à criação de subcentralidades periféricas, o que torna a análise mais complexa.

Os imóveis destinados à faixa 1 do PMCMV contêm certas particularidades, como o fato de serem adquiridos por meio de um sorteio realizado pelas prefeituras das cidades nas quais os empreendimentos estão inseridos. Outra particularidade diz respeito à propriedade, pois, ao ser sorteado, o beneficiário que foi contemplado pode usufruir do imóvel para a sua moradia e de sua família e, dentro de um prazo de 120 meses, segue pagando mensalidades à Caixa Econômica Federal, com prestações subsidiadas e sem juros ao longo do período.

No tempo em que o imóvel permanece alienado à Caixa Econômica Federal por meio do financiamento, não pode haver nenhum tipo de comercialização da moradia. 0 imóvel só pode ser vendido ou alugado quando estiver totalmente quitado, o que só é possível após o período total do financiamento (120 meses), pois, se for quitado antes, há a perda do subsídio recebido. Mesmo assim, já são observadas práticas de venda e de locação dessas moradias.

Este trabalho se propõe a analisar as operações de venda e de locação no PMCMV, focando na faixa 1, no município de Parnamirim, que integra a Região Metropolitana (RM) de Natal. Para a realização desta pesquisa, fez-se uso de referências dos principais autores nacionais sobre o tema, acesso às leis que regulam o programa, coleta e tabulação de anúncios de venda e de locação de imóveis enquadrados nessa categoria, pesquisa de campo e notícias divulgadas na imprensa.

O trabalho está estruturado da seguinte forma: primeiramente, haverá uma descrição do PMCMV e suas características no território nacional; em seguida, serão expostos os elementos legais que regulamentam a propriedade no período de financiamento; na sequência, serão tratados os reflexos do mercado sobre o valor de uso e de troca nos imóveis; por fim, será discutido o programa na RM de Natal, em particular da prática de venda e de locação dos imóveis no município de Parnamirim. 


\section{O Programa Minha Casa Minha Vida}

Em 2009, por meio da Lei no 11.977, foi lançado o PMCMV, integrante da proposta do Programa de Aceleração do Crescimento (PAC), criado em 2007 com o intuito de alavancar a economia do Brasil por causa da crise iniciada nos Estados Unidos, que se difundia em âmbito global.

O programa, além de objetivar a geração de emprego e de renda no setor da construção civil e de toda a cadeia produtiva que esse setor abrange, busca oferecer habitação às famílias com um teto salarial de até dez salários mínimos, dado o alto déficit habitacional dessa população. O PMCMV foi dividido em três faixas, segundo o nível de renda familiar, sendo a faixa 1 destinada às famílias com renda de até três salários mínimos, e as faixas 2 e 3, às famílias com renda entre três e dez salários mínimos. As regras que regulamentam a faixa 1 se distinguem em alguns aspectos das outras duas faixas, assim como os subsídios designados a esses imóveis. Para aquisição dos imóveis da faixa 1, é necessário se cadastrar na prefeitura da cidade em que reside e ser sorteado, para então ter acesso ao imóvel. Uma das exigências impostas à população da faixa 1 é não possuir outro imóvel. 0 programa também privilegia a população que mora em áreas de risco. 0 subsídio nessa faixa pode chegar a 95\% do valor do imóvel, e o saldo devedor é financiado em 120 meses sem juros. Segundo Cardoso et al. (2017), além de entender a habitação como um bem com estrito valor de uso, o programa estimula o valor de troca dela por meio da dinâmica do mercado:

O PMCMV se estrutura sobre um modelo de mercantilização do bem que se propõe a ofertar a moradia a partir da transferência (ou aquisição) da propriedade do bem. Um primeiro impacto sobre a sustentabilidade do programa diz respeito ao fato de que, uma vez transferido, o bem tem um valor de mercado, o que permitiria ao beneficiário capitalizar o valor monetariamente, transferindo-o para outra pessoa. Isso pode significar - e ocorre frequentemente - que essa transferência implique em um desvio em relação aos objetivos sociais do programa, já que acabariam sendo beneficiadas pessoas de faixas de renda mais elevadas, que se aproveitariam dos subsídios promovidos. Por conta desse problema, o programa estabelece um conjunto de limitações visando evitar transferências prematuras, mas há sempre o risco de transações realizadas informalmente (Cardoso et al., 2017, p. 42-43).

A Lei no 11.977 , em seu artigo 6ํㅡ, trata das subvenções concedidas aos beneficiários do programa, que tem como um de seus objetivos "facilitar a aquisição do imóvel residencial". Também traz, no parágrafo $5^{\circ}$, as regras para os subsídios à faixa 1 do programa.

$\S 5$ o Nas operações com recursos previstos no caput:

I - a subvenção econômica será concedida nas prestações do financiamento, ao longo de 120 (cento e vinte) meses;

II - a quitação antecipada do financiamento implicará o pagamento do valor da dívida contratual do imóvel, sem a subvenção econômica conferida na forma deste artigo;

III - não se admite transferência inter vivos de imóveis sem a respectiva quitação (Brasil, 2009).

Primeiramente, a lei esclarece que o prazo de financiamento é de dez anos, sem a cobrança de juros no período; em seguida, expõe que a quitação do imóvel antecipadamente pode fazer com que o proprietário perca o subsídio concedido, tendo, assim, de pagar o valor integral do imóvel. Adiciona ainda que não é possível transferi-lo antes de ter sido totalmente quitado e que qualquer tipo de contrato é considerado ilegítimo fora das condições previamente estabelecidas.

\section{Financiamento e comercialização dos imóveis do PMCMV}

Ao ser sorteado pela prefeitura de sua cidade e contemplado com um imóvel do PMCMV faixa 1, o beneficiário assina um contrato de financiamento do saldo devedor com a Caixa Econômica Federal. No período do financiamento, de 120 meses, a unidade habitacional da faixa 1 fica alienada ao Fundo de 
Arrendamento Residencial (FAR), vinculado à Caixa Econômica Federal, e o proprietário não pode vender nem alugar o seu imóvel (CEF, 2012). Essa restrição é colocada para que não haja transferência do benefício concedido a determinado grupo familiar, o qual se encontra em uma situação financeira de maior vulnerabilidade, a outros grupos com maiores rendimentos. Portanto, no que tange ao direito de propriedade dos beneficiados pelo programa em relação ao imóvel, segundo Freitas (2015), caracteriza-se como propriedade limitada, pois destina a "outrem algumas das elementares ou atributos da propriedade, como o instituto do usufruto, da hipoteca". A alienação fiduciária, segundo Chalhub (2017), não é simplesmente a "troca de um bem por dinheiro, mas a destinação de um bem a uma função", tendo como resultado final do período de financiamento a incorporação desse bem ao patrimônio do beneficiário ou, no caso de inadimplência, a volta do bem ao patrimônio do fiduciante. Assim, o direito de propriedade sobre o imóvel financiado por meio de alienação fiduciária contém restrições até que o bem seja totalmente quitado.

Embora as regras expressas na lei, no contrato em que assinam e em diversos instrumentos de comunicação da Caixa Econômica Federal deixem claro que a finalidade do programa é oferecer habitação às famílias contempladas com o imóvel subsidiado e que qualquer tipo de contrato de cessão de direitos não tem validade legal, observam-se, por meio de pesquisas de campo, anúncios ou reportagens, a comercialização e/ou a locação das moradias. Os beneficiários realizam essa operação por intermédio de um contrato de compra e venda, mais conhecido como "contrato de gaveta".

Segundo Freitas (2015), o "contrato de gaveta" é um documento confeccionado pelos próprios negociantes, no qual consta a transação efetuada pelo vendedor do imóvel, o qual tem o dever de, acabado o período em que o imóvel permanece financiado, transferir a titularidade para o comprador, que, no ato da compra, lança mão de um valor negociado com o dono do imóvel e assume o financiamento daquele período em diante (Freitas, 2015).

Esse tipo de contrato não é ato exclusivo dos financiamentos do PMCMV faixa 1 . 0 repasse de imóveis por meio de contratos informais, ou seja, sem o devido registro no cartório de imóveis, tem ocorrido sem a anuência do órgão financiador. Em outras palavras, um imóvel financiado fica alienado ao banco credor pelo período em que a dívida permanece. Para que o proprietário possa vender ou repassar esse imóvel, é necessário que haja uma autorização da instituição financiadora, porém o financiamento é recalculado, e as parcelas assumidas pelo novo devedor sofrerão reajustes, o que desestimula o processo do repasse do financiamento imobiliário de forma legal. Dessa forma, para os financiamentos imobiliários em vigor, existe a possibilidade de se fazer a transferência de proprietário de forma legal por meio de trâmites que envolvem o banco credor (CEF, 2016).

Porém, no que tange ao financiamento dos imóveis da faixa 1 do PMCMV, não existe a possibilidade de repasse ou venda. Como já mencionado, os imóveis dessa faixa são destinados a uma população de menor rendimento e que enfrenta maiores obstáculos para adquirir uma moradia. Assim, são designados subsídios a essas famílias, a fim de que elas possam ter acesso a esse bem para o uso próprio. É com base nessa transferência de recursos que o programa não permite que seus beneficiários comercializem os imóveis contemplados. 0 entendimento de alguns autores (Cardoso et al., 2017) é que os subsídios destinados à moradia de famílias mais carentes são transferidos a famílias com maiores rendimentos, à medida que os imóveis forem sendo vendidos, não atingindo, assim, o intuito social a que se destina. Em vista disso, o repasse, a venda ou o aluguel dos imóveis da faixa 1 do programa são ilegais, sendo os acordos realizados apenas por meio dos contratos informais.

\section{Valor de uso e valor de troca dos imóveis}

O que se pretende apresentar com essas descrições é o valor que a habitação representa, por um lado, na ótica do proprietário e, de outro, na visão do trabalhador/morador. Havendo a necessidade de se habitar em localidades próximas ao lugar de trabalho e sendo a oferta de imóveis pequena para suprir a grande procura, pela lógica de mercado capitalista essas moradias tendem a ter seu preço 
elevado. Mesmo sendo esse valor oneroso em demasia para o trabalhador, em razão de sua necessidade, ele é obrigado a sujeitar-se e pagar altos preços de aluguéis por habitações precárias. Sendo assim, a habitação possui um valor de troca na perspectiva do proprietário, que tem no imóvel uma mercadoria capaz de lhe render lucro. Porém, para o morador que usufrui e consome o direito de moradia da casa, o valor é de uso. Dessa forma, a casa é uma mercadoria no mercado capitalista, possuindo valor de uso e valor de troca.

O acesso a uma moradia adequada, a qual disponha de condições apropriadas de sobrevivência humana, é, no Brasil, assim como em vários lugares do mundo, um problema histórico, acentuado, em grande parte, pela urbanização das cidades. Em 1844, Engels (2010) publicou uma pesquisa relatando como a classe operária vivia no período. 0 autor começou seu relato em Londres, passou por várias cidades industriais e detalhou a condição de moradia na cidade de Manchester. As descrições são de habitações que acomodavam muito mal a população mais pobre, tanto em termos de conforto como nos quesitos relativos à higiene. Habitações insalubres, úmidas, pequenas para a grande quantidade de pessoas que comportavam e inseridas em bairros com péssimas condições de infraestrutura e higiene.

Nas grandes cidades brasileiras, ocorreu o mesmo fenômeno. Vaz (1994) relatou a conjuntura da cidade do Rio de Janeiro no fim do século XIX e início do século XX, descrevendo as habitações que alojavam a grande massa de trabalhadores que se aglomerava nessa cidade. A descrição novamente era de habitações insalubres e com alta densidade, com nenhum cuidado higiênico, sendo foco de variadas doenças que não se limitavam aos bairros mais pobres. Na capital paulista, o cenário se repetia nos cortiços.

Tanto nas moradias insalubres da Inglaterra como nas habitações das cidades brasileiras, destaca-se o alto rendimento obtido pelos proprietários de terra ou imóveis com o aluguel de péssimas moradias a famílias mais pobres. A situação dos centros das cidades brasileiras começou a se alterar por meio de medidas higienistas. Apesar disso, a situação de moradia dos trabalhadores não foi modificada, mas somente transferida de lugar, como já exposto por Engels (1984, p. 41-43):

Na realidade, a burguesia tem apenas um método para resolver à sua maneira a questão da habitação - isto é, resolvê-la de tal forma que a solução produza a questão sempre de novo [...] 0 resultado é em toda a parte o mesmo, por mais diverso que seja o pretexto: as vielas e [os] becos mais escandalosos desaparecem ante grande autoglorificação da burguesia por esse êxito imediato, mas... ressuscitam logo de novo em qualquer lugar e frequentemente na vizinhança imediata. [...] Os focos de epidemias, as mais infames cavernas e buracos em que o modo de produção capitalista encerra noite após noite os nossos operários não são eliminados, mas apenas... mudados de lugar!.

Harvey (1980, p. 135), ao qualificar o "valor de uso e o valor de troca do solo e das benfeitorias", salienta que as moradias não são como qualquer outra mercadoria, mas sim especiais, requerendo, portanto, a observação de alguns aspectos que fazem especiais os valores de uso e de troca contidos nelas, a saber:

- permanência e probabilidade de vida, sendo o solo e suas benfeitorias uma "oportunidade de acumular riqueza";

- uso que se dá por um longo período de tempo;

- diversos modos de utilização, conforme a necessidade e o perfil de seus usuários. Segundo o autor (Harvey, 1980, p. 136), uma casa pode servir de abrigo, como espaço para uso exclusivo de seus ocupantes, privacidade, localização de serviços, trabalho, vizinhança, fontes de poluição ou aspectos negativos e como meio de lucrar e aumentar a riqueza.

Além dessas características, existem diversos grupos de atores envolvidos no mercado imobiliário, como as instituições financeiras, as instituições governamentais, os incorporadores, as indústrias da construção, os usuários da moradia, os corretores, entre outros. Portanto, o valor que se atribui ao solo ou ao imóvel será diferente, dependendo da perspectiva de cada grupo em particular, sendo que "[...] o que é valor de uso para um é valor de troca para outro [...]" (Harvey, 1980, p. 140). Porém, apesar de, para certos grupos (em especial para os que fazem uso da moradia), o valor de uso ser sobrepujante, eles não se 
encontram isentos de ter suas vidas ou moradias determinadas pela lógica mercadológica, ou seja, por fatores que direcionam o mercado imobiliário na busca de maiores lucros, isto é, maiores valores de troca. O local em que estiver inserido o lugar de moradia dos indivíduos contará também com a dinâmica e a pressão da especulação imobiliária e com a valorização ou a desvalorização que a acompanha. Sobre a lógica que acompanha o mercado de solo urbano, Harvey (1980, p. 162) argumenta:

Os valores de troca relacionam-se (através da circulação de mercadorias) aos valores de uso socialmente determinados. Se argumentarmos que a renda pode prescrever o uso, então isso implica que os valores de troca podem determinar os valores de uso, criando novas condições, às quais os indivíduos devem adaptar-se se desejarem sobreviver em sociedade. [...] 0 mercado capitalista de economia de troca penetra tanto em cada aspecto da vida social e privada que exerce controle quase tirânico sobre o sistema de sustentação da vida, nos quais os valores de uso estão inseridos.

Valença (2003) destaca que a casa é uma mercadoria, pois está à disposição do mercado para compra e venda. Essa mercadoria, porém, possui especificidades próprias, que a diferenciam das outras. Segundo o autor, a habitação é uma necessidade básica, e, no seu interior, ocorre a convivência com a família e os amigos, sendo ela essencial à sobrevivência humana. Essa mercadoria também é caracterizada pelo alto valor agregado e sua complexa produção, por causa do número de agentes envolvidos, do longo tempo de produção ou da oferta limitada no curto prazo. 0 autor ainda destaca a sua fixidez geográfica, enfatizando que é uma mercadoria que não se muda de lugar. Ainda salienta a pouca frequência com que a mercadoria casa muda de propriedade.

O PMCMV, ao subsidiar imóveis para a população de baixa renda, objetiva dar acesso à casa própria para famílias que não poderiam adquirir esse bem sem a intermediação do Estado. A Fundação João Pinheiro divulgou em seu relatório sobre o déficit habitacional que, no ano de 2014, da população total deficitária de moradia, 83,9\% faziam parte do grupo com menores rendas (até três salários mínimos). Portanto, ao se facilitar o acesso à moradia à população com menor renda por meio da faixa 1 do programa, tem-se a finalidade de oferecer habitação com valor de uso a esse grupo populacional. As regras que restringem a comercialização desses imóveis buscam conter a pressão exercida pelo mercado por intermédio da especulação. No entanto, indaga-se: em que medida essas regras conseguem conter essas forças? Essa finalidade defende realmente o interesse e a necessidade da população contemplada pelo programa?

\section{Recursos metodológicos}

Para além do mero ato de comercialização do imóvel, esta pesquisa investigou as dinâmicas que caracterizam os beneficiários e os impulsionam a vender ou locar os imóveis com os quais foram contemplados. A pesquisa abordou a conduta de venda e de locação nos imóveis da faixa 1 do PMCMV no município de Parnamirim, localizado na RM de Natal, o segundo maior em população (202.456 habitantes) depois de Natal (803.739 habitantes). A delimitação da pesquisa em Parnamirim se justifica por ser o município onde mais unidades habitacionais foram entregues nas fases 1 e 2 , no Estado do Rio Grande do Norte.

Para a realização desta pesquisa, além da pesquisa bibliográfica, os seguintes recursos metodológicos foram utilizados: pesquisa de campo e coleta de anúncios on-line. 


\section{Pesquisa de campo}

Pesquisa realizada entre os meses de fevereiro a março de 2018, por meio de aplicação de questionários nos empreendimentos do PMCMV faixa 1 na RM de Natal ${ }^{1}$. Essa pesquisa de campo foi realizada pelo grupo Cidades Contemporâneas do DPP/UFRN, tendo sido desenhada e coordenada pelos professores Márcio Moraes Valença e Sara Raquel Fernandes Queiroz de Medeiros. Foram aplicados 882 questionários, com uma margem de 3\% de erro e 95\% de nível de confiança, segundo cálculo estatístico realizado pelo Laboratório de Estatística Aplicada da Universidade Federal do Rio Grande do Norte (LEA/UFRN). Desse total de questionários, 333 foram realizados na cidade de Parnamirim, que contém 4.224 unidades na faixa 1 do PMCMV ${ }^{2}$. 0 Quadro 1 apresenta o total das unidades em cada empreendimento e a amostra calculada para cada um deles.

Quadro 1. Número total e amostra dos empreendimentos de Parnamirim

\begin{tabular}{|c|c|c|c|}
\hline Município & Empreendimento & Total de unidade & $\begin{array}{c}\text { Tamanho amostral - } \\
\text { margem de erro de 3\% }\end{array}$ \\
\hline Parnamirim & Residencial Nelson Monteiro & 352 & 28 \\
\hline Parnamirim & Residencial Waldemar Rolim & 496 & 39 \\
\hline Parnamirim & Residencial Vida Nova & 464 & 37 \\
\hline Parnamirim & Residencial llhas do Pacífico & 432 & 34 \\
\hline Parnamirim & Residencial América I & 496 & 39 \\
\hline Parnamirim & Residencial América II & 496 & 39 \\
\hline Parnamirim & Residencial llhas do Atlântico & 496 & 39 \\
\hline Parnamirim & Residencial Terras do Engenhol & 496 & 39 \\
\hline Parnamirim & Residencial Terras do Engenho II & 496 & 39 \\
\hline & Total & $\mathbf{4 2 2 4}$ & $\mathbf{3 3 3}$ \\
\hline
\end{tabular}

Fonte: elaboração própria a partir dos cálculos amostrais realizados pelo LEA/UFRN.

\section{Coleta de anúncios on-line e tabulação de dados}

A pesquisa contou também com o monitoramento semanal no site de classificados on-line OLX. 0 procedimento de acesso ao site se deu desde o mês de dezembro de 2016, por meio de busca de imóveis do PMCMV faixa 1 na RM de Natal. Os imóveis foram identificados como pertencentes ao programa mediante descrição dos próprios vendedores e/ou por intermédio de fotos divulgadas nos anúncios. Após a coleta, cada publicação foi catalogada, e todas as informações foram tabuladas conforme as descrições disponíveis, tais como: a operação (venda ou aluguel), a tipologia do imóvel, o tamanho, o preço, o empreendimento, a cidade, entre outros.

\section{Estudo de caso: o PMCMV em Parnamirim}

Parnamirim é o terceiro maior município do Estado do Rio Grande do Norte, estando atrás de Natal (capital) e Mossoró, que fica no oeste potiguar. Na RM de Natal, é o segundo maior município, com uma população de 202.456 habitantes. Parnamirim possui alta integração com Natal e, segundo Freire et al. (2015, p. 115), de 1991 até 2010, aumentou a sua participação relativa de 7,1\% para 15\% da população

\footnotetext{
${ }^{1}$ A pesquisa de campo faz parte de uma pesquisa maior envolvendo os grupos de pesquisa Cidades Contemporâneas e Estúdio Conceito do Departamento de Políticas Públicas da UFRN e engloba as pesquisas de dissertação de três alunas do Programa de Pós-Graduação em Estudos Urbanos e Regionais (PPEUR/UFRN), sendo uma delas o projeto da autora.

${ }^{2}$ A amostragem estatística foi calculada considerando a população de cada um dos empreendimentos em separado, para que, ao fazer uma análise individual, seja do empreendimento, seja do município, o cálculo do tamanho amostral não fosse afetado.
} 
total da RM de Natal. 0 município está localizado no litoral potiguar e faz limite territorial com Natal, Macaíba, São José de Mipibu e Nísia Floresta, conforme ilustra a Figura 1.



Figura 1. Localização do município de Parnamirim/RN. Fonte: grupo de estudos Cidades Contemporâneas da UFRN (2018).

A RM de Natal é composta de 14 municípios 3 , dos quais nove foram contemplados com o PMCMV, por meio de 51 empreendimentos em 21 localidades diferentes. Em Parnamirim, foram entregues 4.224 unidades, o que corresponde a mais de $38 \%$ do total de habitações entregues na RM de Natal, até o ano de 2016, e foram nove empreendimentos (Quadro 2) entregues em um intervalo de seis anos (2011 e 2016), período que compreende as fases 1 e 2 do PMCMV, e em cinco localidades diferentes (Figura 2).

Quadro 2 - Empreendimentos do PMCMV em Parnamirim entregues até 2016

\begin{tabular}{|c|c|c|c|c|}
\hline Localização & Empreendimento & Unidades & Tipologia & Ano de entrega \\
\hline Nova Esperança & Residencial Nelson Monteiro & 352 & Apartamento & 2011 \\
\hline Nova Esperança & Residencial Waldemar Rolim & 496 & Apartamento & 2011 \\
\hline Passagem de Areia & Residencial Vida Nova & 464 & Apartamento & 2012 \\
\hline Passagem de Areia & Residencial Ilhas do Pacífico & 432 & Apartamento & 2013 \\
\hline Nova Esperança & Residencial América I & 496 & Apartamento & 2012 \\
\hline Nova Esperança & Residencial América II & 496 & Apartamento & 2012 \\
\hline Nova Esperança & Residencial Terras do Engenhol & 496 & Apartamento & 2013 \\
\hline Nova Esperança & Residencial Terras do Engenho II & 496 & Apartamento & 2013 \\
\hline Liberdade & Residencial llhas do Atlântico & 496 & Apartamento & 2016 \\
\hline
\end{tabular}

Fonte: dados dos grupos de estudos Cidades Contemporâneas e Estúdio Conceito da UFRN.

\footnotetext{
${ }^{3}$ Os municípios que compõem a RM de Natal são: Arês, Ceará-Mirim, Extremoz, Goianinha, Ielmo Marinho, Macaíba, Maxaranguape, Monte Alegre, Natal, Nísia Floresta, Parnamirim, São Gonçalo do Amarante, Macaíba e Vera Cruz.
} 


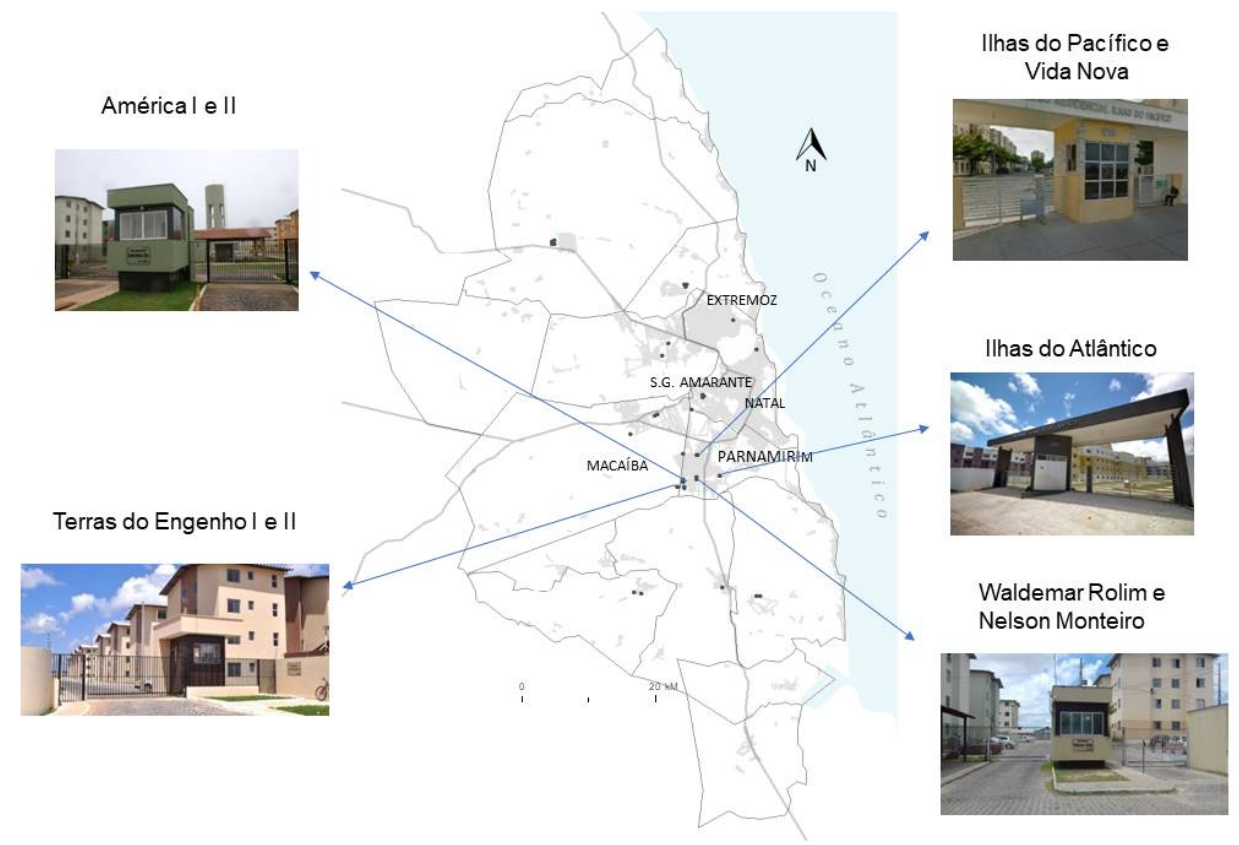

Figura 2 - Localização dos empreendimentos da faixa 1 do PMCMV em Parnamirim/RN. Fonte: grupo de estudos Cidades Contemporâneas da UFRN (2018).

Todas as unidades habitacionais entregues em Parnamirim eram apartamentos em conjuntos de vários blocos, como demonstrado na Figura 3, e estavam alocadas na forma de condomínios fechados, com portaria e acesso restrito. Embora os nove empreendimentos estivessem localizados em áreas distantes do centro da cidade, apenas dois residenciais (inseridos na mesma localidade) estavam desconectados da malha urbana já constituída, sendo visualizados de forma isolada: os residenciais Terras do Engenho I e II.

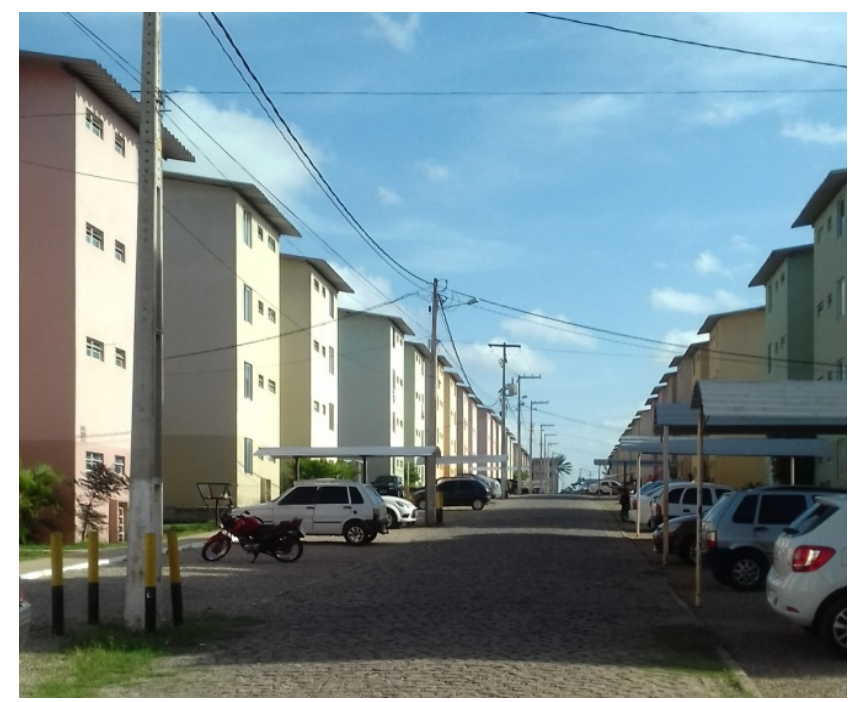

Figura 3 - Interior do residencial Waldemar Rolim, em Parnamirim. Fonte: grupo de estudos Cidades Contemporâneas da UFRN (2018).

A pesquisa de campo realizada demonstrou que, no município de Parnamirim, $77 \%$ dos imóveis do PMCMV faixa 1 eram resididos pelos proprietários, enquanto 13,4\% eram alugados. Os residenciais que mais possuíam imóveis alugados eram Terras do Engenho II, com 25\%, Waldemar Rolim, com 20,5\%, e Nelson Monteiro, com 21,5\%. Quando indagados sobre a nova condição de moradia em comparação à 
anterior, $84 \%$ dos entrevistados disseram que houve uma melhora nas condições gerais de moradia. Ao se questionar aspectos relacionados ao residencial e seus espaços coletivos, assim como as características da unidade habitacional, os níveis de satisfação foram elevados, com taxas de $71 \%$ e $82,4 \%$, respectivamente. No aspecto tamanho, $62 \%$ da população moradora dos empreendimentos PMCMV faixa 1 de Parnamirim relatou que houve uma melhora em comparação com a habitação anterior. Porém, sobre a localização do imóvel atual, 55\% afirmaram que ocorreu uma melhora, enquanto $45 \%$ responderam que piorou a situação locacional, ao comparar com à moradia anterior. No entanto, os resultados referentes à localização nos nove empreendimentos foram heterogêneos, como pode ser observado no Quadro 3.

Quadro 3 - Localização do residencial em relação à moradia anterior

\begin{tabular}{|c|c|c|}
\hline Empreendimento & Melhorou \% & Piorou \% \\
\hline Residencial Vida Nova & 83 & 23 \\
\hline Residencial Nelson Monteiro & 77 & 26 \\
\hline Residencial Waldemar Rolim & 74 & 27 \\
\hline Residencial llhas do Pacífico & 73 & 45 \\
\hline Residencial América I & 55 & 54 \\
\hline Residencial América II & 46 & 61 \\
\hline Residencial Terras do Engenho I & 39 & 67 \\
\hline Residencial llhas do Atlântico & 33 & 73 \\
\hline
\end{tabular}

Fonte: pesquisa de campo dos grupos de estudos Cidades Contemporâneas e Estúdio Conceito (2018).

Os residenciais com maiores satisfações em relação à localidade (Vida Nova, Nelson Monteiro, Waldemar Rolim e Ilhas do Pacífico) eram os que se encontravam situados em regiões com maior integração urbana, serviços e infraestrutura urbana. No entanto, distinta foi a situação dos residenciais Terras do Engenho I e II e Ilhas do Atlântico, que tiveram altos índices de insatisfação quanto à localidade. Os residenciais Terras do Engenho I e II, em particular, estavam localizados em região desconectada da malha urbana, como pode ser visto na Figura 4.

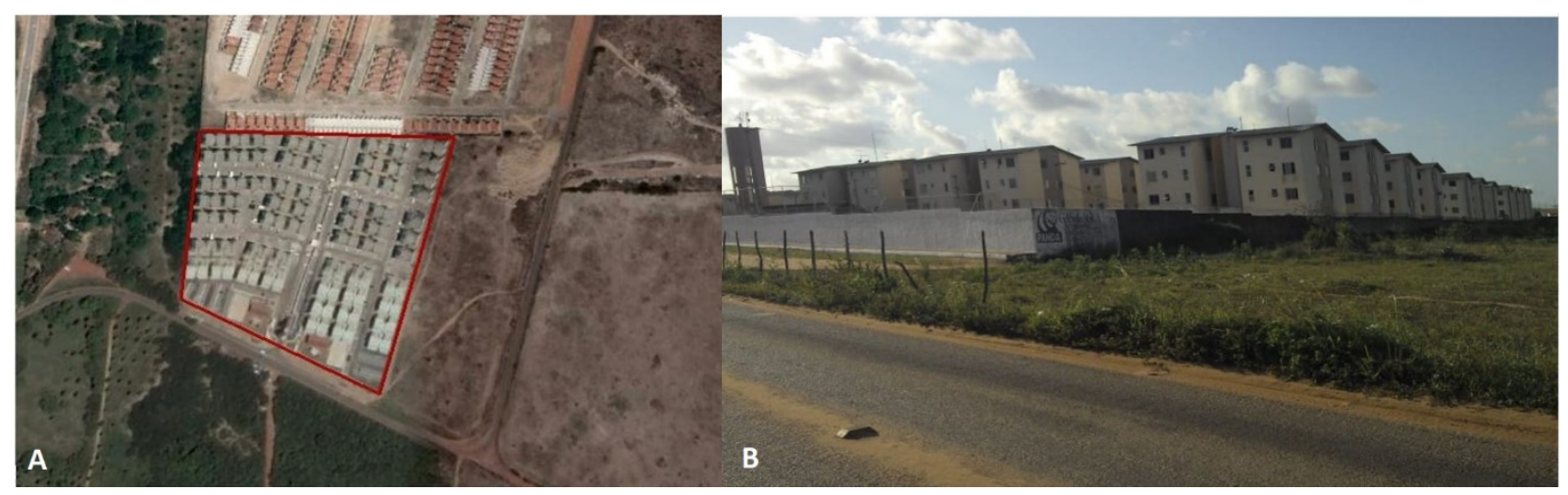

Figura 4 - Residenciais Terras do Engenho I e ll. Fonte: grupo de estudos Cidades Contemporâneas da UFRN (2018).

Quando indagados se tinham conhecimento de imóveis à venda ou para locação no empreendimento, 67,5\% dos entrevistados responderam positivamente. Os residenciais com maiores respostas positivas quanto à comercialização de imóveis foram Ilhas do Pacífico, com 82\%, Nelson Monteiro, com 78,5\%, e Waldemar Rolim, com 77\%.

Outra etapa da pesquisa se deu na forma de coleta de anúncios em classificados on-line de vendas e locações. Foi utilizado o site da OLX, filtrando os resultados de imóveis para o Estado do Rio Grande do Norte. A coleta dos dados obedeceu aos seguintes procedimentos: primeira etapa, busca do termo "Minha Casa Minha Vida"; segunda etapa, exclusão dos empreendimentos das faixas 2 e 3, inserindo os 
nomes dos empreendimentos da faixa 1, filtrando os resultados e listando os imóveis que estavam à venda ou para locação.

Foram coletados 148 anúncios que ofertavam locação e comercialização dos imóveis empreendidos para a faixa 1. De todos os anúncios, 146 estavam vinculados aos proprietários, havendo somente dois com o envolvimento de instituições formais (imobiliárias e corretores de imóveis).

Do total de anúncios coletados on-line para toda a RM de Natal, 70\% estavam localizados em Parnamirim. Ao se analisar os anúncios de imóveis para locação ou venda no município, observa-se, no Gráfico 1, que 41\% eram referentes aos residenciais Terras do Engenho I e II, e 17\%, aos residenciais América I e II, que se encontravam no mesmo bairro dos residenciais Terras do Engenho I e II, porém mais bem localizados quanto à proximidade de comércios, escolas e infraestruturas de serviços. Nos residenciais Nelson Monteiro e Waldemar Rolim (ambos na mesma localidade), o percentual foi de 30\% dos anúncios coletados. Os outros $12 \%$ se dividiram entre outros residenciais (Ilhas do Atlântico, Ilhas do Pacífico e Vida Nova), sendo que o residencial Ilhas do Atlântico foi entregue há pouco mais de um ano.



Gráfico 1 - Distribuição dos anúncios de imóveis do PMCMV faixa 1 em Parnamirim. Fonte: elaboração própria.

Dos anúncios coletados em Parnamirim, 79\% eram de venda, e 21\%, de locação. 0 valor dos aluguéis estava entre $R \$ 200,00$ e $R \$ 400,00$, sendo seu valor médio de $R \$ 330,00$, abaixo do preço do mercado imobiliário do município. 0 preço médio de aluguel para apartamentos de dois quartos em Parnamirim nos últimos 12 meses foi de $\mathrm{R} \$ 819,52$, segundo o Expo Índice (2017b) (Figura 5).

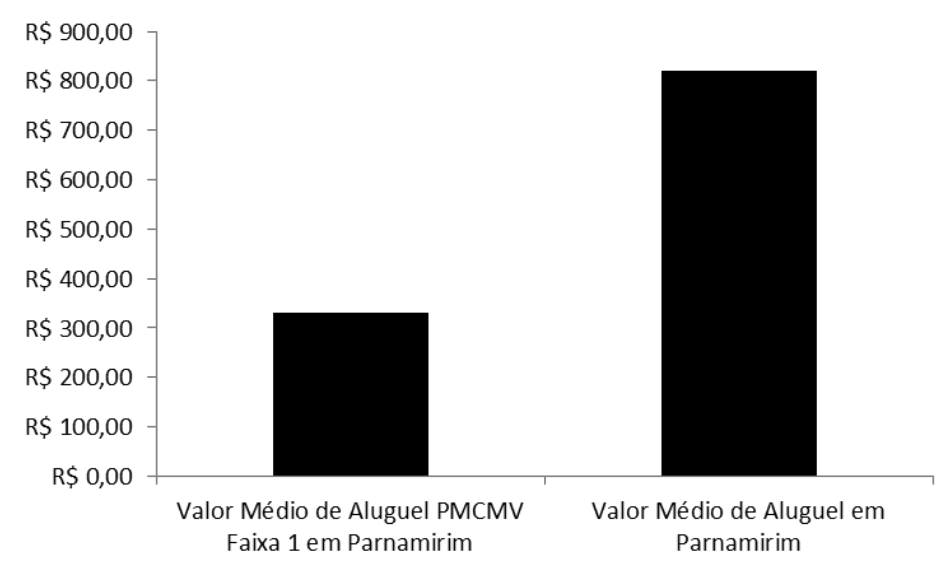

Figura 5 - Valor médio de aluguel de apartamentos em Parnamirim. Fonte: elaboração própria. 
Segundo esse mesmo índice (Expo Índice, 2017a), o preço médio para aquisição de apartamentos (no padrão de tamanho aos anunciados) era de $\mathrm{R} \$ 158.931,00$. Os valores de venda dos imóveis anunciados do PMCMV faixa 1 variavam entre $\mathrm{R} \$ 14.500,00$ e $\mathrm{R} \$ 30.000,00$ para os residenciais Terras do Engenho I e II. Nos residenciais Nelson Monteiro e Waldemar Rolim, o valor de venda estava entre $\mathrm{R} \$ 25.000,00$ e $\mathrm{R} \$ 60.000,00$, e variava de $\mathrm{R} \$ 15.000,00$ a $\mathrm{R} \$ 22.000,00$ nos residenciais América I e II. 0 valor médio de venda desses imóveis era de $\mathrm{R} \$ 29.600,00$, conforme demonstra a Figura 6.

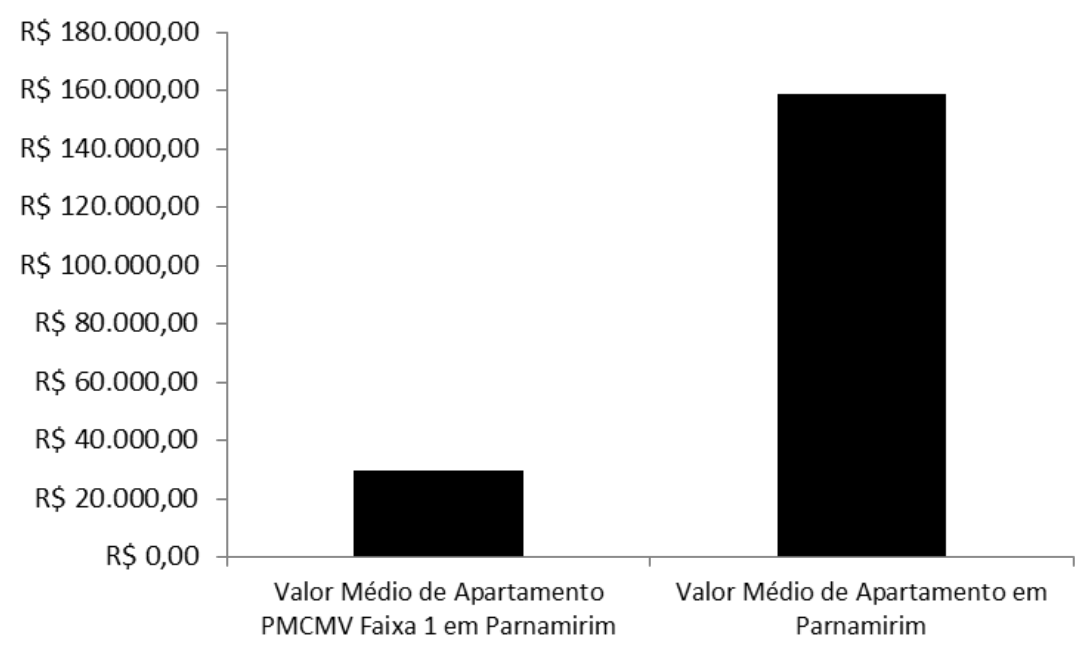

Figura 6 - Valor médio de venda de apartamentos em Parnamirim. Fonte: elaboração própria.

Dos resultados obtidos, pode-se concluir que os residenciais que mais tiveram anúncios de imóveis para vender e locar se encontravam em duas situações. Uma se refere à localização, que foi o caso dos residenciais Terras do Engenho I e II, que se situavam mais isolados e restritos ao acesso à infraestrutura e a serviços. A segunda observação diz respeito à valorização imobiliária, pois a segunda localidade que mais disponibilizou anúncios foram os residenciais Nelson Monteiro e Waldemar Rolim, que eram os mais antigos e, por serem os primeiros entregues no município, estavam inseridos em uma região de acelerado crescimento, tendo à sua volta acesso a comércios e serviços públicos e sendo uma região que se valorizava e atraía uma classe de rendimento maior.

\section{Conclusões}

O PMCMV é um importante instrumento de política pública com intuito de subsidiar moradia para as famílias de baixa renda, pois, em razão do alto valor da mercadoria casa e da vulnerabilidade econômica de muitas dessas famílias, somente por meio de políticas de auxílio habitacional seria possível se alcançar uma moradia adequada. O programa tem sido estudado em variadas regiões do Brasil e acompanhado segundo as particularidades de cada localidade (Cardoso \& Aragão, 2013; Amore et al., 2015). Sua magnitude e seus subsídios são elencados como fatores positivos, assim como a localização das moradias é apontada como elemento negativo. Contudo, deve-se ressaltar que, no caso de Parnamirim, de nove residenciais entregues pelo PMCMV, apenas dois encontravam-se mal localizados. Entretanto, o nível de satisfação dos moradores, mesmo nos empreendimentos que estavam mal localizados, foi alto.

No que diz respeito à venda e à locação de imóveis nesses empreendimentos, fica evidente que tanto a má quanto a boa localização são fatores que podem incentivar a prática de comercialização das moradias. No caso da localização inadequada, as famílias não têm ao seu entorno condições suficientes para a rotina diária, como acesso a transportes públicos, postos de saúdes e hospitais, comércios, outros serviços e infraestruturas urbanas. Todavia, habitações com uma boa localização também podem 
incentivar a comercialização, as quais, dada a regra, seriam somente para o uso de seu beneficiário e sua família. À medida que a localidade se valoriza e recebe ações especulativas, o valor de troca do imóvel pode exceder ao valor de uso para o seu beneficiário.

Acerca das regras que regulamentam o programa, fixar as famílias em um só lugar, considerando o grupo social e econômico em que elas se enquadram, pode ser uma forma equivocada de se realizar uma política pública de assistência habitacional. A situação de local de trabalho é um fator que leva famílias com remunerações mais baixas a estar em constante mudança de residência, pois se encontram mais suscetíveis a mudanças de emprego. Segundo Pochmann (2009, p. 46), "[...] no Brasil, a rotatividade atinge mais os postos de trabalho com empregados de menor remuneração". Outro aspecto digno de investigação é quanto ao reflexo do mercado imobiliário, gerando estímulos ou pressões que resultam na substituição das famílias atendidas pelo programa e, consequentemente, expulsão delas, fazendo com que voltem para situações de moradias inadequadas e insalubres, de onde muitas dessas famílias possam ter saído.

Com base nas observações, é válido refletir se a dinâmica de localização dos empreendimentos do PMCMV gera somente uma segregação urbana ou se, ao longo do tempo, com a valorização e a especulação imobiliária, via investimento público, pode fomentar a gentrificação desses novos conjuntos habitacionais. Faz-se necessária também a reflexão sobre como oferecer habitação adequada às famílias de baixa renda além da alternativa da propriedade privada da moradia, para que essas habitações não se transformem em meras mercadorias manipuladas pelas forças do mercado.

\section{Referências}

Amore, C. S., Shimbo, L. Z., \& Rufino, M. B. C. (Orgs.) (2015). Minha Casa... e a Cidade? Avaliação do Programa Minha Casa Minha Vida em seis estados brasileiros. Rio de Janeiro: Letra Capital.

Brasil. (2009, 8 de julho). Dispõe sobre o Programa Minha Casa, Minha Vida-PMCMV e a regularização fundiária de assentamentos localizados em áreas urbanas; altera o Decreto-Lei no 3.365, de 21 de junho de 1941, as Leis nos 4.380, de 21 de agosto de 1964, 6.015, de 31 de dezembro de 1973, 8.036, de 11 de maio de 1990, e 10.257, de 10 de julho de 2001, e a Medida Provisória no 2.197-43, de 24 de agosto de 2001; e dá outras providências. Brasília: Diário Oficial da União. Recuperado em 1 agosto de 2017, de http://www.planalto.gov.br/ccivil_03/_ato2007-

2010/2009/lei/111977.htm

Caixa Econômica Federal - CEF. (2012). Cartilha Completa sobre o Programa Minha Casa Minha Vida. Brasília: Caixa Econômica Federal.

Caixa Econômica Federal - CEF. (2016). Posso vender meu imóvel financiado pelo Minha Casa Minha Vida? Agência Caixa de Notícia.

Cardoso, A. L., \& Aragão, T. A. (2013). Do fim do BNH ao Programa Minha Casa Minha Vida: 25 anos da política habitacional no Brasil. In A. L. Cardoso (Org.), O programa Minha Casa Minha Vida e seus efeitos territoriais. Rio de Janeiro: Letra Capital.

Cardoso, A. L., Aragão, T. A., \& Jaenisch, S. T. (2017). Vinte e dois anos de Política Habitacional no Brasil: da euforia à crise. In A. L. Cardoso, T. A. Aragão, \& S. T. Jaenisch (Orgs.), Vinte e dois anos de Política Habitacional no Brasil: da euforia à crise. Rio de Janeiro: Letra Capital/Observatório das Metrópoles.

Chalhub, M. N. (2017). Alienação fiduciária de bens imóveis. Recuperado em 2 janeiro de 2018, de http://civileimobiliario.web971.uni5.net/wp-content/uploads/2017/04/Aliena\%C3\%A7\%C3\%A3o-

Fiduci\%C3\%A1ria-AASP-2017.pdf

Engels, F. (1984). Para a questão da habitação. Lisboa: Edições Avante.

Engels, F. (2010). Situação da classe trabalhadora na Inglaterra. São Paulo: Boitempo.

Expo Índice. (2017a). Preço Médio de Revenda de Apartamentos em Parnamirim-RN. Recuperado em 1 de julho de 2017, de https://www.expoimovel.com/preco-imovel/revenda/apartamentos/RN/parnamirim 
Expo Índice. (2017b). Preço Médio de Aluguel de Apartamentos em Parnamirim - RN. Recuperado em 1 de julho de 2017, de https://www.expoimovel.com/preco-imovel/aluguel/apartamentos/RN/parnamirim

Freire, F. H. M. A., Gonzaga, M. R., \& Ojima, R. (2015). Dinâmica demográfica da Região Metropolitana de Natal. In M. L. M. Clemetino, \& A. L. Ferreira (Ed.), Natal: Transformações na Ordem Urbana (pp. 113-142). Rio de Janeiro: Letra Capital.

Freitas, R. A. (2015). Carência regulatória do contrato de gaveta. Frutal: Prospectiva.

Harvey, D. (1980). A justiça social e a cidade. Rio de Janeiro: OLX. Recuperado em 2 janeiro de 2018, de https://rn.olx.com.br/imoveis

Pochmann, M. (2009). 0 trabalho na crise econômica no Brasil: primeiros sinais. Estudos Avançados, 23(66), 41-52. http://dx.doi.org/10.1590/S0103-40142009000200004.

Valença, M. M. (2003). Habitação: notas sobre a natureza de uma mercadoria peculiar. Cadernos Metrópole, (9), 165-171.

Vaz, L. F. (1994). Dos cortiços às favelas e aos edifícios de apartamentos - a modernização da moradia no Rio de Janeiro. Analise Social, 29(127), 581-597.

Editor: Rodrigo Firmino.

Recebido: Fev. 13, 2018

Aprovado: Out. 30, 2018 